\title{
TRÍPODE FENICIO PROCEDENTE DE LA COSTA DE VÉLEZ-MÁLAGA.
}

\author{
por \\ JUAN ANTONIO MARTÍN RUIZ \\ EMILIO MARTÍN CÓRDOBA
}

\section{INTRODUCCIÓN}

Un descubrimiento casual realizado por parte de unos pescadores mientras faenaban nos permite dar a conocer un hallazgo vinculable al mundo fenicio que, aunque aislado y carente de un contexto preciso con el que poder relacionarlo, no está, sin embargo, exento de interés como tendremos ocasión de comprobar en los párrafos que siguen.

En efecto, al izar las redes pudieron comprobar cómo éstas habían recogido un recipiente cerámico que pasó a formar parte de una colección privada cuyo propietario, D. José Reina, decidió finalmente donarlo integrándose así en la colección arqueológica depositada en el Ayuntamiento de Vélez-Málaga.

Sin embargo, no es ésta la primera vez que se tienen noticias acerca de la aparición de restos submarinos en esta estrecha franja del litoral malagueño, pues la utilización de redes de arrastre hace que no sean hechos infrecuentes, sin que por desgracia sea habitual que se comunique su hallazgo como ha sucedido en esta ocasión, máxime cuando se trata de una zona en la que se ubican varias ciudades con una clara vocación marítima, tanto de época fenicia como romana (Maionoba, Caviclum...).

Como decimos con anterioridad se conocía la presencia, cerca de la costa, de un pecio en el espacio comprendido entre los asentamientos de Chorreras y Morro de Mezquitilla (Martínez y Martínez 1987: 249). Datable hacia mediados o, a lo sumo, el último tercio del siglo IV a. C., transportaba un cargamento que, por lo que sabemos, incluía cinco ánforas, dos de ellas pertenecientes al tipo T.11.2.1.4 de la clasificación establecida por J. Ramón (1995: 80), en tanto las restantes se adscriben al T-12.1.1.1, estando destinadas al almacenamiento de salazones de pescado. 


\section{EL HALLAZGO ARQUEOLÓGICO}

En concreto se trata de un trípode cerámico que ha llegado hasta nosotros completo, salvo alguna pequeña fractura en su borde de escasa importancia, el cual fue recuperado en la costa de Vélez-Málaga, en un punto situado frente al yacimiento de Morro de Mezquitilla cuya localización exacta desconocemos. Tras ser sometido a un proceso de limpieza a fin de eliminar las concreciones marinas que llevaba adheridas pudo verse que carece de decoración, como por otra parte suele ser norma en estos recipientes, lo que no excluye que en el sur peninsular a veces puedan aparecer pintados, gris monócromo o cubiertos de engobe rojo (Pachón, Carrasco 1991-92: 343). Mide 282 mm de diámetro máximo y 110 de altura, con un grosor de pared de entre 15-17 mm. Presenta, como es lógico, tres pies macizos de tendencia trapezoidal. Su borde, bajo el cual arrancan directamente los pies, muestra una sección triangular con engrosamiento al exterior en el que se aprecia una hendidura que lo separa del cuerpo. Con pasta color gris, presenta un desgrasante fino a grueso en el que se advierten abundantes restos de cuarcitas (lámina I).

Bajo su fondo, y a ambos lados de uno de sus pies, se advierten dos líneas incisas de 25 y $50 \mathrm{~mm}$ de longitud respectivamente, y entre 2 y $5 \mathrm{~mm}$ de ancho, ejecutadas con anterioridad a la cocción, y que tal vez cabría poner en relación con algún sistema de suspensión del objeto mediante pequeñas cuerdas.

Dada la carencia total de contexto que nos permita establecer su cronología, hemos de tomar en consideración sus características formales, como son especialmente la forma del borde o la situación de los pies directamente bajo éste, las cuales lo relacionan con otros ejemplares localizados en yacimientos del mediodía peninsular, en particular con los documentados en Castillo de Doña Blanca (Ruiz, Pérez 1995: 57 y 82), Casa de Montilla (Schubart 1987: 222 y 224), Morro de Mezquitilla (Schubart 1979: 195) y Chorreras (Aubet 1979: 116; Gran-Aymerich 1981: 3), sin que olvidemos el fragmento localizado en la fase III del hábitat del Cerro de la Mora (Pachón y Carrasco 1991-92: 332), aunque menos preciso en este sentido. Todo ello nos llevaría a otorgarle una cronología bastante temprana, como sería el siglo VIII a. C., si bien no hemos de olvidar que en el siglo VI a. C. existen ejemplos de trípodes que muestran una tendencia arcaizante (Maass-Lindemann 1986: 238), lo que hace que tampoco pueda excluirse esa fecha.

\section{CONCLUSIONES}

Como es bien sabido, estos trípodes, también llamados cuencos-trípode o cuencos-mortero, son piezas de indudable origen oriental que provienen de modelos hechos en piedra, siendo así que en esa zona los fabricados en cerámica no parece que llegaran a competir con los pétreos (Culican 1970: 11). En la Península Ibérica son escasos los ejemplares documentados en las primeras décadas de la implantación fenicia, siendo a partir del siglo VII a. C. cuando aumente su frecuencia de aparición, hasta el presente restringida a las zonas de hábitat pues no se conocen trípodes en sus necrópolis, de forma similar a lo que acontece en el ámbito indígena, si bien en esta ocasión es posible encontrarlos en alguna que otra sepultura, como sucede en el túmulo de Entremalo (Culican 1970: 11).

Aún no está del todo clara cuál fue su funcionalidad, aunque cada día parece imponerse entre los investigadores la creencia de que, al menos entre los fenicios occidentales, se trata de artefactos vinculados, más que con cuestiones de índole ritual, con labores domésticas muy similares a las que cumplían los morteros y que viene avalada por los contextos habitacionales en que éstos aparecen (Pachón y Carrasco 1991-92: 345-346).

Así mismo, podemos constatar cómo la carencia de tratamiento decorativo que muestra este trípode se ajusta a la tendencia observada en todos los recipientes de este tipo que han aparecido en los enclaves fenicios, tendencia que contrasta con lo que vemos en las comunidades autóctonas contemporáneas, en las que, aún siendo también predominantes los vasos no decorados, es posible hallar, no obstante, una mayor variedad ornamental. 


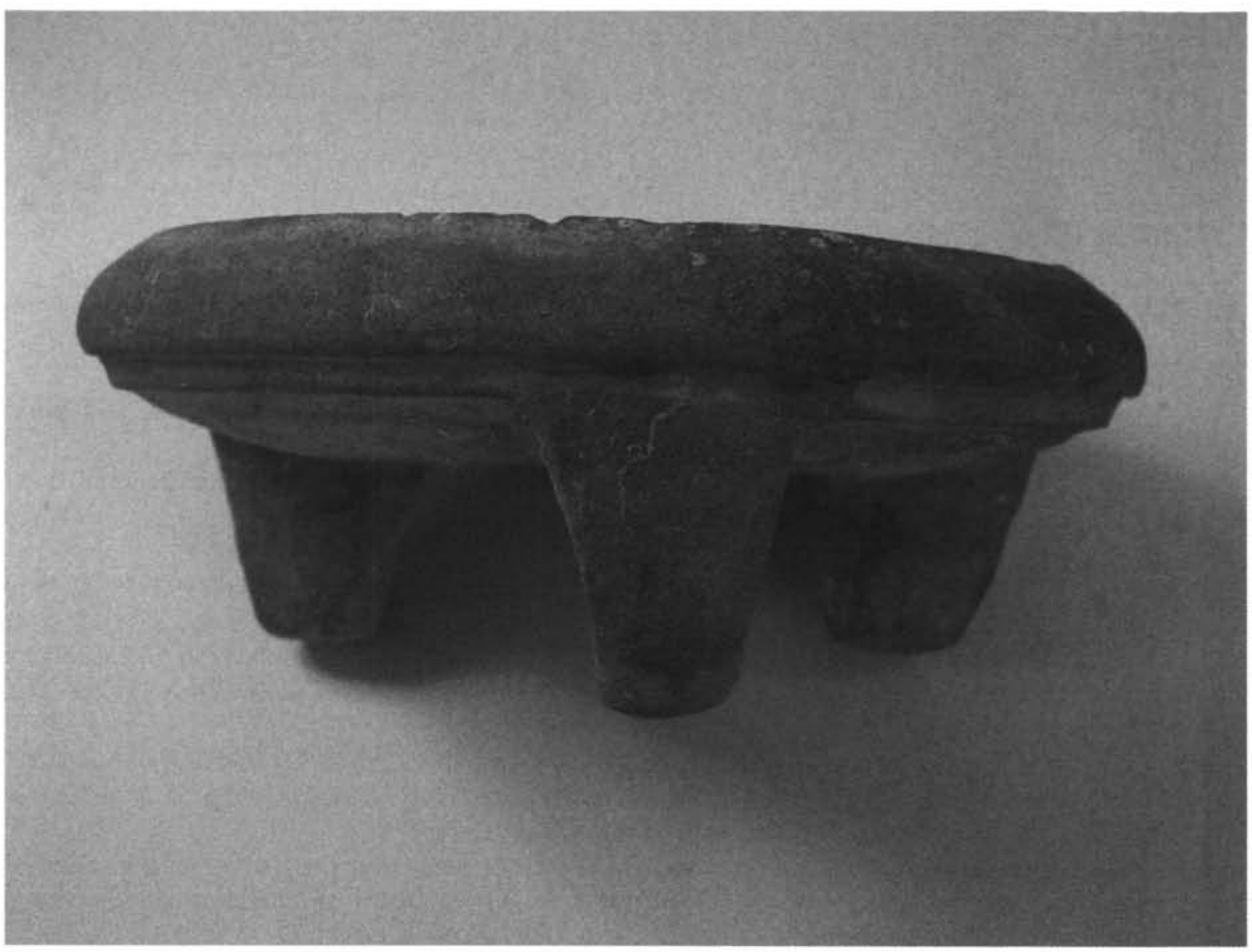

Lámina I

Este hallazgo parece confirmar la existencia en estas aguas de un segundo navío fenicio, el cual podría denominarse Morro de Mezquitilla-2 a fin de diferenciarlo del anteriormente conocido. Nos encontraríamos, pues, con dos navíos con cronologías muy dispares, como es el siglo IV a. C. para el primero y, quizás, el siglo VIII si no el VI a. C. para el que ahora damos a conocer, en todo caso más antiguo que Morro-1.

Por otra parte hemos de decir que la presencia de este tipo de piezas no es en modo alguno extraña en los cargamentos marinos recuperados pertenecientes a navegantes semitas, según se ha constatado en otros navíos como pueden ser el pecio de Mazarrón B-1 (Negueruela et alii, 2000: 1672 y 1677) o el de Bajo de la Campana I (Mas 1985: 156), ambos hundidos en las costas levantinas y con una datación del siglo VII en el primer caso y el VI para el segundo. De todas formas, los estudios sobre el tema aún no han podido establecer si estos trípodes formaban parte únicamente del cargamento transportado para su ulterior comercialización, o bien también eran empleados por los tripulantes en sus actividades diarias, habida cuenta que la mayor parte de los pecios citados no han sido excavados o carecemos de las publicaciones detalladas sobre los mismos.

En definitiva, podemos decir que la aparición de esta pieza nos permite, además de contar con un nuevo ejemplar cerámico de trípode completo fechable en el siglo VIII o VI a. C., obtener, y ello es lo más importante, nueva información sobre el proceso colonizador fenicio en Vélez-Málaga, pues nos señala la existencia 
de un pecio hasta ahora desconocido situado en un área frente a Morro de Mezquitilla. Su cronología, necesitada por otra parte de una confirmación rigurosa que sólo puede realizarse mediante su excavación, hace que, con los datos disponibles, sea uno de los barcos fenicios más antiguos de los detectados en este sector del Mediterráneo occidental.

\section{BIBLIOGRAFÍA}

AUBET SEMMLER, M. E. (1979): "Chorreras. Un establecimiento fenicio al este de la desembocadura del Algarrobo", Noticiario Arqueológico Hispánico 6: 91-138.

CULICAN, W. (1970): "Phoenician oil bottles and tripod bowls", Berytus XIX: 5-16.

GRAN-AYMERICH, J.M. J.(1981): "Excavaciones arqueológicas en la región de Vélez-Málaga", Noticiario Arqueológico Hispánico 12: 300-373.

MARTÍNEZ DÍAZ, S. y MARTÍNEZLILLO, S. (1987): “Informe preliminar de la $2^{\text {a }}$ campaña de prospecciones Carta Arqueológica submarina de Málaga a Almuñécar", Anuario Arqueológico de Andalucía 1986, vol. II: 249 , Sevilla.

MAS, J. (1985): "El polígono submarino de Cabo de Palos. Sus aportaciones al estudio del tráfico marítimo antiguo", en VI Congreso Internacional de Arqueología Submarina: 153-171, Madrid.

MAASS-LINDEMANN, G. (1986): "Vasos fenicios de los siglos VIII-VI en España. Su procedencia y posición dentro del mundo fenició occidental", en Los fenicios en la Península lbérica vol. I: 227-239, ed. Ausa, Sabadell.

NEGUERUELA, I.; PINEDO, J.; GÓMEZ, M.; MIÑANO, A.; ARELLANO, I. y BARBA, J. S. (2000): "Descubrimiento de dos barcos fenicios en Mazarrón (Murcia)", en Actas del IV Congreso Internacional de Estudios Fenicios y Púnicos vol. IV: 1671-1679, Cádiz.

PACHÓN ROMERO, J. A. y CARRASCORUZ, J.(1991-92): "Un elemento concreto de la cultura material orientalizante en el mediodía peninsular: los cuencos trípodes hallados en el interior de la provincia de Granada", Cuadernos de Prehistoria de la Universidad de Granada 11-12: 325-351.

RAMÓN TORRES, J.(1995): Las ánforas fenicio-púnicas del Mediterráneo central yoccidental, Barcelona. RUIZ MATA, D. y PÉREZ, C. (1995): El poblado fenicio del Castillo de Doña Blanca (El Puerto de Santa María, Cádiz): El Puerto de Santa María.

SCHUBART, H. (1979): "Morro de Mezquitilla. Informe preliminar sobre la campaña de excavaciones de 1976", Noticiario Arqueológico Hispánico, 6: 177-218.

(1987): "Hallazgos fenicios y del Bronce Final en la desembocadura del río Guadiaro(Cádiz)", Anuario Arqueológico de Andalucía 1986 vol.II: 200-227, Sevilla. 